\title{
Plasma apelin levels in obstructive sleep apnea and the effect of continuous positive airway pressure therapy
}

\author{
David E Henley ${ }^{1,2}$, Fiona Buchanan ${ }^{3}$, Rosemary Gibson ${ }^{3}$, Jennie A Douthwaite ${ }^{1}$, Susan A Wood ${ }^{1}$, \\ Wolfram W Woltersdorf ${ }^{4}$, James $\mathbf{R}$ Catterall ${ }^{3}$ and Stafford L Lightman ${ }^{1}$ \\ ${ }^{1}$ Henry Wellcome Laboratories for Integrative Neuroscience and Endocrinology, University of Bristol, Bristol BS1 3NY, UK \\ ${ }^{2}$ Faculty of Medicine, Dentistry and Health Sciences, University of Western Australia, Crawley 6009, Western Australia, Australia \\ ${ }^{3}$ Departments of Respiratory Medicine and ${ }^{4}$ Clinical Biochemistry, University Hospitals Bristol, Bristol BS1 3NU, UK \\ (Correspondence should be addressed to D E Henley who is now at Department of Endocrinology and Diabetes, Sir Charles Gairdner Hospital, 1st Floor, \\ C-Block, Hospital Avenue, Nedlands, Western Australia 6009, Australia; Email: dhenley@cygnus.uwa.edu.au)
}

\begin{abstract}
Apelin is a peptide hormone with cardiovascular and glucose homeostasis properties, and obstructive sleep apnea (OSA) is complicated by cardiovascular and metabolic comorbidities. Plasma apelin has not been previously assessed in OSA. We investigated the response of plasma apelin to a $2-\mathrm{h} 75 \mathrm{~g}$ oral glucose tolerance test (OGTT) and the effect of 3 months compliant continuous positive airway pressure (CPAP) therapy in 15 obese males with newly diagnosed OSA. Plasma apelin and serum cortisol were recorded 10 minutely, while serum insulin and glucose were measured 30 minutely. Ten subjects had plasma apelin measured at intervals across a 24-h period to investigate for circadian variation in apelin levels, and this was repeated following 3 months compliant CPAP therapy. Fasting $(0.342 \pm 0.038$ vs 0.288 $\pm 0.024 \mathrm{ng} / \mathrm{ml}, P=0.04), 30 \mathrm{~min}(0.399 \pm 0.035$ vs 0.312 $\pm 0.036 \mathrm{ng} / \mathrm{ml}, P=0 \cdot 007)$ and $120 \mathrm{~min}(0.402 \pm 0.030 \mathrm{vs}$
\end{abstract}

$0 \cdot 259 \pm 0.024 \mathrm{ng} / \mathrm{ml}, P<0 \cdot 001)$ apelin levels were reduced following CPAP. The area under curve for apelin OGTT response was lower post-CPAP $(44 \cdot 1 \pm 3 \cdot 3$ vs 35.8 $\pm 2 \cdot 3 \mathrm{ng} / \mathrm{ml}$ per min, $P<0 \cdot 001)$. Mean OGTT apelin levels showed a significant treatment effect $(P=0 \cdot 006)$ and a time effect $(P<0 \cdot 001)$, and the effect of time was different preversus post-CPAP $(P=0 \cdot 005)$. No significant variability in apelin levels existed across the $24-\mathrm{h}$ period at diagnosis. Lower levels were evident overnight following treatment $(P=0 \cdot 004)$. Improvements in insulin and glucose parameters and reduced cortisol levels were found post-CPAP. In summary, untreated OSA was associated with elevated plasma apelin levels, altered apelin secretory dynamics in response to oral glucose and lack of an apparent circadian variability, which was restored following CPAP.

Journal of Endocrinology (2009) 203, 181-188

\section{Introduction}

Obstructive sleep apnea (OSA) is a common condition, with an estimated prevalence of $3-7 \%$ for adult men and $2-5 \%$ for adult women in the general population (Punjabi 2008). It is associated with intermittent upper airway obstruction and subsequent hypoxia and autonomic arousal during sleep, resulting in fragmented sleep with daytime somnolence (Buckley \& Schatzberg 2005). Morbidity and mortality from OSA are primarily due to cardiovascular disease (Peter et al. 1995, Collop 2007), but it is also independently associated with an increased prevalence of the metabolic syndrome (Coughlin et al. 2004) and impaired glucose metabolism (Seicean et al. 2008). These may be ameliorated with continuous positive airway pressure (CPAP) therapy (Harsch et al. 2004, Bradley \& Floras 2009).

Apelin is a novel peptide hormone discovered in 1998 using reverse pharmacology and was first isolated from bovine

stomach extract (Tatemoto et al. 1998). It is produced as a 77-amino acid prepropeptide that is cleaved to C-terminal fragments of varying size including apelin-13, apelin-17 and apelin-36 (Tatemoto et al. 2001, Kleinz \& Davenport 2005). All apelin peptides activate APJ (listed as APLNR in Hugo Database), an orphan G-protein-coupled receptor, which shares about 30\% homology with the angiotensin (AT-1a) receptor (O'dowd et al. 1993). However, ATII does not bind to APJ.

Apelin may have an important role in respiratory physiology. There are relatively high amounts of APJ receptor mRNA located in the rat medulla oblongata (Hosoya et al. 2000), and microinjections of apelin-13 into the nucleus tractus solitarius result in apnea (Seyedabadi et al. 2002). Apelin and Apj mRNA are highly expressed in the rat lung suggesting a paracrine effect in this tissue (Hosoya et al. 2000, Kawamata et al. 2001). Plasma apelin levels are reduced in patients with chronic, severe parenchymal lung disease and 
preserved cardiac function (Goetze et al. 2006). In a rat model of chronic hypoxic pulmonary hypertension, apelin protein concentration in lung tissue decreased, although total pulmonary apelin content remained stable as a result of a corresponding increase in pulmonary tissue mass, with evidence of altered downstream signalling from the APJ receptor (Andersen et al. 2009).

Apelin is found in the myocardium (Foldes et al. 2003) and endothelial cells (Kleinz \& Davenport 2004) and has several cardiovascular properties including regulation of blood pressure (Tatemoto et al. 2001, Lee et al. 2005), cardiac contractility (Szokodi et al. 2002, Ernst et al. 2006) and possibly fluid balance (Chandrasekaran et al. 2008). It has also recently been shown to be an adipokine secreted from adipocytes (Boucher et al. 2005) and is thought to be involved in glucose homeostasis and obesity (Boucher et al. 2005, Dray et al. 2008). Circulating levels are altered in subjects with impaired glucose metabolism (Li et al. 2006, Erdem et al. 2008) and dyslipidaemia (Tasci et al. 2007). Given these observations, we conducted a study to investigate apelin levels in obese patients with newly diagnosed OSA and examined the effect of compliant CPAP therapy.

\section{Materials and Methods}

\section{Subjects}

Fifteen male patients were recruited from the Sleep Disorders Clinic and participated in the study after provision of written informed consent approved by the Bath Research Ethics Committee. Each was newly diagnosed with OSA following overnight polysomnography (Alice 5, Respironics (UK) Ltd, Chichester, UK) with continuous recording of electroencephalogram, electromyogram, electrooculogram, nasal airflow, body position, thoracic and abdominal respiratory efforts and arterial oxyhaemoglobin saturation recorded by pulse oximeter and were analysed according to established criteria (Rechtschaffen et al. 1968). An apnea was defined as a $10 \mathrm{~s}$ cessation of breathing, and a hypopnea was defined as a $10 \mathrm{~s}$ decrease of $50 \%$ or more in airflow measured by nasal-oral cannulae. Arousals and desaturations were not included in the scoring of hypopneas. According to the apnea-hypopnea index (AHI), patients were included with either moderately severe (AHI 15-30) or severe (AHI $>30, n=13$ ) OSA.

Other inclusion criteria included: normal physical examination; body mass index (BMI) $\geq 30$; normal renal, liver and thyroid function. Specific exclusion criteria were: any other respiratory disorder; acute illness; symptomatic chronic medical disorder; diabetes mellitus; depression; uncontrolled hypertension; medications known to alter cortisol levels (specifically, any glucocorticoid therapy within the preceding 3 months); AT converting enzyme inhibitor medication; ATII receptor blocker medication; current smoker; alcohol intake of $>21$ units per week.

\section{Anthropomorphic measurements}

Body weight and height were measured by the same observer using a scale and stadiometer to $0.5 \mathrm{~kg}$ and $0.5 \mathrm{~cm}$ respectively. Waist (WC) and hip circumferences were measured to $0.5 \mathrm{~cm}$ with a non-elastic tape using standard techniques (World Health Organisation 2000). The waistto-hip ratio (WHR) was calculated from the ratio of waist and hip circumferences. Neck circumference was measured at the level of the superior border of the cricothyroid cartilage to $0.5 \mathrm{~cm}$. The means of two consecutive recordings were used. Systolic and diastolic blood pressures were measured twice at 5 -min intervals in the sitting position.

\section{Oral glucose tolerance test}

Participants attended in the morning after at least 12-h fasting and were connected to an automated sampling system as previously described (Henley et al. 2009). Briefly, participants attended $1 \mathrm{~h}$ prior to commencement of sampling for cannulation of a suitable peripheral arm vein. This was attached to the sampling system in an adjacent room and a 30-min acclimatisation sequence performed. Blood for plasma apelin and serum cortisol was collected at baseline (fasting) and then $10 \mathrm{~min}$ for $2 \mathrm{~h}$ following a $75 \mathrm{~g}$ oral glucose load. Three baseline samples for serum insulin and glucose were drawn at 5-min intervals (Wallace et al. 2004) for homeostatic model assessment of insulin resistance (HOMA-IR) estimates and then at 30-min intervals after the oral glucose. A fasting lipid profile was also assessed. Following the initial study, participants commenced nasal CPAP therapy (REMstar Auto, Respironics (UK) Ltd), and the exact protocol was repeated 3 months later while using CPAP.

Ten of the participants had serial plasma apelin measurements over a $24-\mathrm{h}$ period to assess for diurnal variation. Samples were drawn at 2200, 0200, 0800, 1200 and $1800 \mathrm{~h}$. This 24-h study, designed to assess ultradian hypothalamicpituitary-adrenal (HPA) axis activity, commenced at $1900 \mathrm{~h}$, and lights were switched off from $2300 \mathrm{~h}$ until $0700 \mathrm{~h}$. Standardised meals were served at 2000, 0800 (after sample drawn) and $1230 \mathrm{~h}$.

\section{Hormone assay}

Samples for apelin were collected in chilled $1 \mathrm{ml}$ EDTA tubes, centrifuged immediately at $4{ }^{\circ} \mathrm{C}$ and then stored at $-80^{\circ} \mathrm{C}$ until assayed. Plasma apelin-12 level was determined by ELISA (Phoenix Pharmaceuticals, Belmont, CA, USA), with a sensitivity of $0.07 \mathrm{ng} / \mathrm{ml}$, intra-assay coefficient of variation (CV) $3 \cdot 8 \%$ and inter-assay $\mathrm{CV}$ $9 \cdot 9 \%$. There is $100 \%$ cross-reactivity with human apelin-12, apelin-13 and apelin-36. Cortisol concentrations were measured by solid phase, competitive chemiluminescent enzyme immunoassay (Immulite 2000, Siemens Medical Solutions, Camberley, UK). Intra- and inter-assay CV were 5.9 and $11 \%$ respectively. Serum insulin was measured by 
electrochemiluminescence immunoassay (Roche Modular, Roche Diagnostics Ltd) with intra- and inter-assay CV of 1.5 and $4.9 \%$ respectively. Glucose was assayed using the enzymatic hexokinase method (Roche Modular, Roche Diagnostics Ltd) with intra- and inter-assay CV of 1.0 and $1 \cdot 7 \%$ respectively. Plasma total cholesterol and triglyceride concentrations were determined enzymatically by cholesterol esterase and lipase hydrolysation respectively using an Olympus AU2700 platform (Watford, UK).

\section{Statistical analysis}

The data are presented as mean \pm s.E.M. KolmogorovSmirnov test was used to determine distribution characteristics. Comparisons of mean values were made with paired $t$-test (or Wilcoxon signed-rank test for non-parametric data). Two-way repeated-measures ANOVA was used to assess serial mean apelin and cortisol data with pairwise multiple comparison via the Holm-Sidak method. One-way repeated-measures ANOVA was used to compare circadian apelin data with pairwise multiple comparison using the Tukey's test. The relationship between variables was analysed by Pearson's correlation (or Spearman's correlation for nonparametric data). All reported $P$ values are two sided, and the significance level was set to $0 \cdot 05$.

\section{Results}

The clinical characteristics of the patients are shown in Table 1 . The mean age was $51 \cdot 2 \pm 2 \cdot 7$ years (range $34-65$ ). There were no significant differences in anthropomorphic measurements or lipid profile at diagnosis compared with post-CPAP therapy. Systolic and diastolic blood pressures were significantly reduced after CPAP treatment. There was a significant reduction in the AHI and Epworth Sleepiness Scale consistent with successful CPAP therapy. CPAP usage was determined objectively with an internal compliance meter.

\section{Oral glucose tolerance test}

Table 2 summarises the plasma apelin and serum insulin, glucose and cortisol levels in response to the oral glucose tolerance test (OGTT). Basal (fasting), 30 and 120 min apelin levels were reduced following CPAP therapy (Fig. 1A). There was also a significant reduction in the area under curve (AUC) for apelin after CPAP (Fig. 1B). The mean plasma apelin at 30 min was significantly higher than the baseline level preCPAP $(0.399 \pm 0.035$ vs $0.342 \pm 0.028 \mathrm{ng} / \mathrm{ml}, P=0.02)$, but not after treatment $(0.312 \pm 0.026$ vs $0.288 \pm 0.024 \mathrm{ng} / \mathrm{ml}$, $P=0 \cdot 45$ ). Two-way repeated-measures ANOVA of mean plasma apelin levels during the OGTT found a significant treatment effect $(P=0 \cdot 006)$ and time effect $(P<0 \cdot 001)$, as well as a different effect of time pre- versus post-treatment
Table 1 Demographic and clinical data

\begin{tabular}{|c|c|c|}
\hline & Baseline & $\begin{array}{l}3 \text { Months } \\
\text { post-CPAP }\end{array}$ \\
\hline \multicolumn{3}{|l|}{ Variable } \\
\hline Age (years) & $51 \cdot 2 \pm 2 \cdot 7$ & - \\
\hline $\mathrm{BMI}\left(\mathrm{kg} / \mathrm{m}^{2}\right)$ & $36 \cdot 1 \pm 1 \cdot 3$ & $36 \cdot 1 \pm 1 \cdot 3$ \\
\hline WC (cm) & $118 \cdot 7 \pm 2 \cdot 8$ & $117 \cdot 7 \pm 2 \cdot 9$ \\
\hline WHR & $1 \cdot 0 \pm 0 \cdot 0$ & $1 \cdot 0 \pm 0 \cdot 0$ \\
\hline $\mathrm{SBP}(\mathrm{mmHg})$ & $134 \cdot 7 \pm 3 \cdot 4$ & $127 \cdot 6 \pm 3 \cdot 3 *$ \\
\hline $\mathrm{DBP}(\mathrm{mmHg})$ & $86 \cdot 8 \pm 2 \cdot 1$ & $83 \cdot 7 \pm 1 \cdot 3^{+}$ \\
\hline Total cholesterol $(\mathrm{mmol} / \mathrm{l})$ & $4 \cdot 4 \pm 0 \cdot 3$ & $4 \cdot 4 \pm 0 \cdot 2$ \\
\hline HDL-cholesterol (mmol/l) & $1 \cdot 0 \pm 0 \cdot 1$ & $1 \cdot 0 \pm 0 \cdot 0$ \\
\hline LDL-cholesterol (mmol/l) & $2 \cdot 6 \pm 0 \cdot 3$ & $2 \cdot 6 \pm 0 \cdot 2$ \\
\hline Triglyceride $(\mathrm{mmol} / \mathrm{l})$ & $1 \cdot 8 \pm 0 \cdot 2$ & $1 \cdot 8 \pm 0 \cdot 3$ \\
\hline ESS & $11 \cdot 7 \pm 1 \cdot 2$ & $3 \cdot 5 \pm 0 \cdot 6^{*}$ \\
\hline $\mathrm{AHI}$ & $55 \cdot 0 \pm 5 \cdot 8$ & $3 \cdot 8 \pm 0 \cdot 5^{*}$ \\
\hline Desaturation index (number/h) ${ }^{a}$ & $45 \cdot 3 \pm 9 \cdot 4$ & - \\
\hline Average daily CPAP use (h) & - & $5 \cdot 3 \pm 0 \cdot 3$ \\
\hline CPAP duration (days) & - & $93 \cdot 8 \pm 2 \cdot 2$ \\
\hline
\end{tabular}

$\mathrm{BMI}$, body mass index; WC, waist circumference; WHR, waist-to-hip ratio; SBP, systolic blood pressure; DBP, diastolic blood pressure; HDL, highdensity lipoprotein; LDL, low-density lipoprotein; ESS, Epworth Sleepiness Scale; AHI, apnea-hypopnea index. ${ }^{*} P<0 \cdot 001$ for comparison with baseline value, by paired $t$-test. ${ }^{+} P=0.03$ for comparison with baseline value, by paired $t$-test.

${ }^{\mathrm{a}}$ Desaturation defined as $4 \%$ drop below baseline.

$(P=0 \cdot 005$; Fig. 2$)$, suggesting a change in the secretory dynamics in response to glucose.

There was a significant reduction in the mean fasting insulin level and the AUC during OGTT with CPAP therapy. There was also a significant decrease in HOMA-IR together with a concomitant increase in insulin sensitivity after therapy, but no change in $\beta$-cell function. The mean fasting, 30 and $120 \mathrm{~min}$ glucose levels were significantly lower following $\mathrm{CPAP}$, as was the glucose AUC.

The mean fasting cortisol levels were reduced with CPAP; however, given the pulsatile nature of cortisol release, the significance of this is uncertain. More importantly, the mean AUC for cortisol was reduced, and two-way repeatedmeasures ANOVA of mean cortisol levels during the OGTT revealed a significant treatment effect $(P=0 \cdot 002$; Fig. 3).

Prior to treatment, AHI correlated positively with WC $(r=0.539, P=0 \cdot 04)$, BMI $(r=0 \cdot 618, P=0 \cdot 01)$, fasting insulin $(r=0.529, P=0.04)$, HOMA-IR $(r=0.778, P<0.001)$ and $\beta$-cell function (\%B) $(r=0.662, P=0.01)$, and negatively with insulin sensitivity $(\% \mathrm{~S}) \quad(r=-0 \cdot 780, P<0 \cdot 001)$. Both BMI and WC correlated positively with fasting insulin $(r=0.562, \quad P=0.03 ; \quad r=0.623, \quad P=0.01$ respectively), HOMA-IR $\quad(r=0.658, \quad P=0.01 ; \quad r=0.712, \quad P=0.004$ respectively), \%B $(r=0.548, P=0.04 ; r=0.606, P=0.02$ respectively) and insulin AUC $(r=0.529, P=0.04$; $r=0.609, P=0.01$ respectively), and negatively with $\% \mathrm{~S}$ $(r=-0.660, P=0 \cdot 01 ; r=-0 \cdot 726, P=0.002$ respectively). Similarly, WHR had a positive correlation with fasting insulin $(r=0.522, \quad P=0.04), \% \mathrm{~B} \quad(r=0.573, \quad P=0.03)$ and insulin AUC $(r=0.600, P=0 \cdot 02)$. The desaturation 
Table 2 Comparison of oral glucose tolerance test (OGTT) hormone levels pre- and post-continuous positive airway pressure (CPAP)

\begin{tabular}{|c|c|c|c|}
\hline & Pre-CPAP & Post-CPAP & $P$ value \\
\hline $30 \mathrm{~min}$ apelin (ng/ml) & $0 \cdot 399 \pm 0 \cdot 035$ & $0 \cdot 312 \pm 0 \cdot 026$ & $0 \cdot 01^{\mathrm{a}}$ \\
\hline $\mathrm{AUC}_{120}$ apelin $((\mathrm{ng} / \mathrm{ml}) \times \min )$ & $44 \cdot 1 \pm 3 \cdot 3$ & $35 \cdot 8 \pm 2 \cdot 3$ & $<0.001$ \\
\hline Fasting insulin $(\mathrm{pmol} / \mathrm{l})$ & $181 \cdot 9 \pm 37 \cdot 4$ & $135 \cdot 8 \pm 30 \cdot 8$ & $0 \cdot 002$ \\
\hline $30 \mathrm{~min}$ insulin $(\mathrm{pmol} / \mathrm{l})$ & $735 \cdot 4 \pm 121 \cdot 7$ & $637 \cdot 4 \pm 102 \cdot 7$ & $0 \cdot 113$ \\
\hline 120 min insulin $(\mathrm{pmol} / \mathrm{l})$ & $935 \cdot 3 \pm 184 \cdot 6$ & $573 \cdot 9 \pm 126 \cdot 7$ & $<0 \cdot 001$ \\
\hline HOMA-\%B & $153 \cdot 4 \pm 19 \cdot 8$ & $143 \cdot 4 \pm 24 \cdot 5$ & $0 \cdot 423$ \\
\hline HOMA-\%S & $48 \cdot 7 \pm 8 \cdot 1$ & $61 \cdot 8 \pm 8 \cdot 3$ & $0 \cdot 02$ \\
\hline Fasting glucose (mmol/l) & $5 \cdot 7 \pm 0 \cdot 2$ & $5 \cdot 2 \pm 0 \cdot 2$ & $<0 \cdot 001^{\mathrm{a}}$ \\
\hline $30 \mathrm{~min}$ glucose $(\mathrm{mmol} / \mathrm{l})$ & $8 \cdot 7 \pm 0 \cdot 5$ & $7 \cdot 9 \pm 0 \cdot 3$ & $<0 \cdot 001^{\mathrm{a}}$ \\
\hline $120 \mathrm{~min}$ glucose $(\mathrm{mmol} / \mathrm{l})$ & $6 \cdot 9 \pm 0 \cdot 6$ & $6 \cdot 2 \pm 0 \cdot 5$ & $<0 \cdot 001^{\mathrm{a}}$ \\
\hline AUC $_{120}$ glucose $((\mathrm{mmol} / \mathrm{l}) \times \mathrm{min})$ & $1003 \pm 55$ & $920 \pm 52$ & $<0.001^{\mathrm{a}}$ \\
\hline
\end{tabular}

$\mathrm{AUC}_{120}$, area under curve from baseline to $120 \mathrm{~min}$; HOMA-IR, homeostasis model assessment of insulin resistance; HOMA-\%B, homeostasis model assessment of $\beta$-cell function; HOMA-\%S, homeostasis model assessment of insulin sensitivity.

${ }^{a}$ Wilcoxon signed rank test.

index (Table 1), which relates to the severity of oxygen desaturation, correlated positively with HOMA-IR $(r=0.696, P=0.02), \% \mathrm{~B}(r=0.658, P=0 \cdot 03)$ and insulin AUC $(r=0 \cdot 607, P=0 \cdot 03)$.

Following CPAP therapy, WC had a negative correlation with fasting apelin $(r=-0.561, P=0.03)$, although the negative correlation for BMI just failed to reach significance $(r=-0.509, P=0 \cdot 05)$. However, both WC $(r=-0.570$, $P=0.02)$ and BMI $(r=-0.588, P=0.02)$ correlated
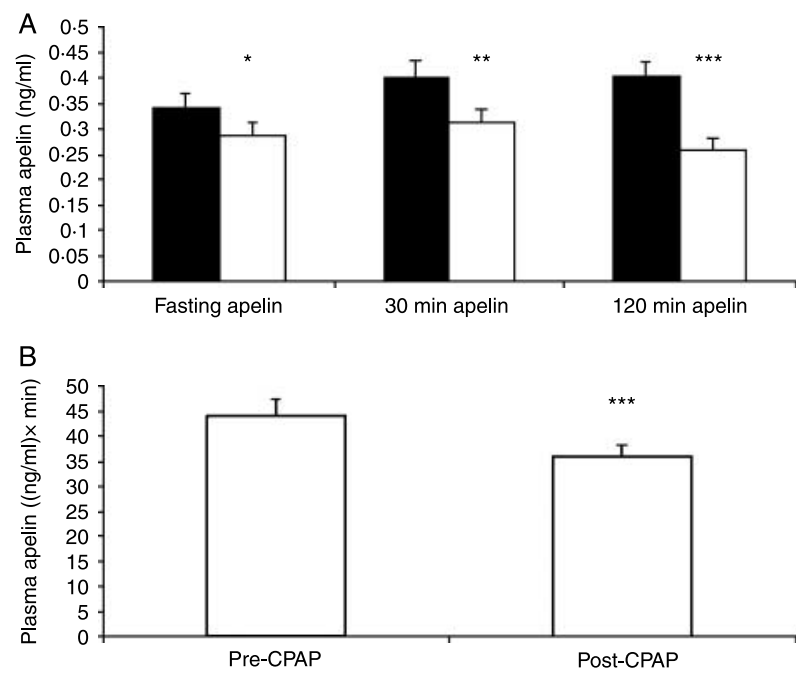

Figure 1 Summary of plasma apelin data. (A) Time-specific plasma apelin levels during OGTT at diagnosis ( $\boldsymbol{\square}$ ) and following 3 months compliant CPAP therapy ( $\square$ ). (B) Plasma apelin area under curve during OGTT similarly before and after treatment. Values are the means \pm S.E.M. ${ }^{*} P=0 \cdot 04,{ }^{* *} P=0 \cdot 01,{ }^{* * *} P<0 \cdot 001$. negatively with apelin AUC. None of these correlations were present at diagnosis. Both $\mathrm{WC}$ and $\mathrm{BMI}$ retained positive correlations with fasting insulin $(r=0 \cdot 722, P=0 \cdot 002$; $r=0.717, P=0.002$ respectively), HOMA-IR $(r=0.689$, $P=0.006 ; r=0.694, P=0.005$ respectively) and insulin AUC $(r=0.565, P=0.03 ; r=0.592, P=0.02$ respectively), as well as the negative correlation with $\% \mathrm{~S}(r=-0.672, P=0.008$; $r=-0 \cdot 667, P=0 \cdot 008$ respectively).

\section{Circadian apelin measurements}

Plasma apelin levels measured at five time points throughout the 24-h period revealed no significant variation across this time domain at diagnosis $(P=0.838$; Fig. 4). However, following 3 months compliant CPAP therapy, one-way repeated-measures ANOVA of mean plasma apelin levels found that the $1800 \mathrm{~h}$ level was significantly higher than both the 2200 and $0200 \mathrm{~h}$ levels $(P<0 \cdot 05)$. Therefore, CPAP may have restored some form of circadian pattern in apelin secretion with the lowest levels overnight.

\section{Discussion}

Patients with OSA have significant cardiovascular and metabolic co-morbidities, and apelin itself is known to have cardiovascular and glucose homeostatic effects, as well as being produced in myocardial, endothelial and adipocyte cells. We found that untreated OSA was associated with significantly elevated apelin levels with evidence of altered secretory dynamics in response to an oral glucose load. Furthermore, for the first time, we provide evidence for a circadian pattern of apelin secretion. 


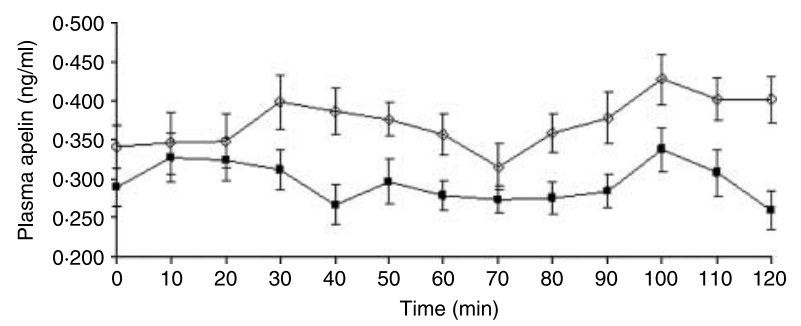

Figure 2 Plasma apelin levels during OGTT at diagnosis $(\diamond)$ and following 3 months compliant CPAP therapy $(\boldsymbol{\square})$. Values are the means \pm S.E.M. of levels at each time point.

Apelin is an adipokine that has been linked to obesity and insulin secretion (Boucher et al. 2005). In this group of obese patients with OSA, we found elevated plasma apelin levels in the fasting state and during a standard 2-h OGTT at diagnosis as compared with 3 months compliant CPAP therapy. There was a significant treatment effect; however, the different effect of time across the OGTT with multiple sampling suggests a difference in secretory dynamics before and after treatment. This patient group is unique compared with other clinical studies on plasma apelin previously reported in other pathophysiologic groups (Boucher et al. 2005, Li et al. 2006, Tasci et al. 2007, Erdem et al. 2008) and supports the view that apelin synthesis/secretion is complex with multiple regulatory factors.

Fasting plasma apelin levels are reported to be increased in obese subjects (Boucher et al. 2005, Heinonen et al. 2005) and to correlate positively with BMI (Heinonen et al. 2005). However, the prevalence of OSA in these subjects was not documented. Other studies in patient groups with newly diagnosed type 2 diabetes (Erdem et al. 2008), isolated hypercholesterolaemia (Tasci et al. 2007) and heart failure (Chong et al. 2006) did not find any correlation of apelin with BMI. Similarly, we found no correlation between fasting plasma apelin and BMI in untreated OSA. However, there was a negative correlation of WC with fasting plasma apelin and both WC and BMI with apelin OGTT AUC after

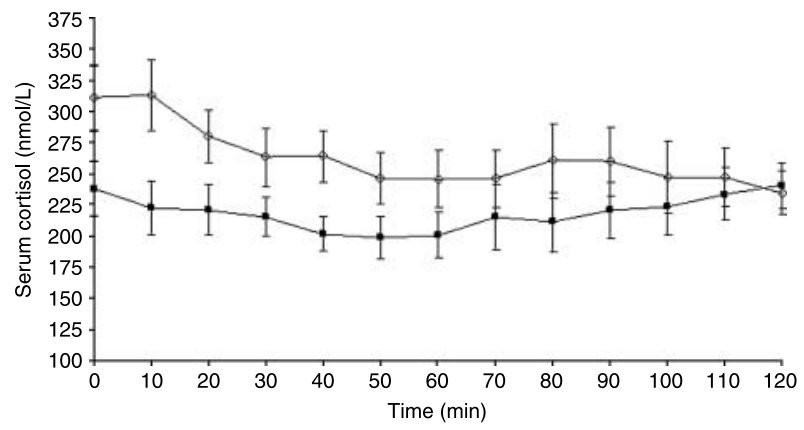

Figure 3 Serum cortisol levels during OGTT at diagnosis $(\diamond)$ and following 3 months compliant CPAP therapy ( $)$. Values are the means \pm S.E.M. of levels at each time point.

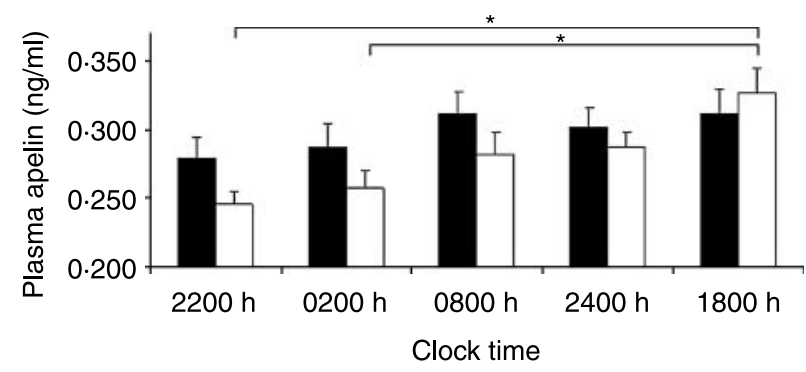

Figure 4 Mean ( \pm S.E.M.) plasma apelin levels recorded at five time points across the 24-h period in ten patients with OSA at diagnosis (ם) and following 3 months compliant CPAP therapy $(\square)$. * $P<0 \cdot 05$.

3 months compliant CPAP therapy. Thus, adiposity per se is unlikely to be a major determinant in circulating apelin levels in different pathophysiological settings. In OSA, other factors such as insulin resistance, oxidative/hypoxic stress, inflammatory cytokines, glucocorticoids and particularly endothelial dysfunction may have a multifactorial role.

Insulin exerts a direct positive action on adipocyte apelin production, and hyperinsulinaemia rather than obesity appears to be the main determinant of adipocyte apelin expression and secretion (Boucher et al. 2005). Apelin has a glucose-lowering effect associated with enhanced glucose utilisation in normal and insulin-resistant murine models (Dray et al. 2008). Thus, it may be postulated that in this group of obese, insulin-resistant patients' apelin is up-regulated to improve glucose utilisation and post-CPAP, with the amelioration of hyperinsulinaemia and improvement in insulin sensitivity, apelin is down-regulated.

Dyslipidaemia modifies plasma apelin levels in nonobese patients with isolated hypercholesterolaemia (Tasci et al. 2007, 2009). In our study, the dyslipidaemia remained unchanged with CPAP therapy and therefore contributed insignificantly to the changes reported in apelin levels. However, the APJ/apelin system appears to have a role in the development of hypercholesterolaemia-associated atherosclerosis (Hashimoto et al. 2007). Therefore, although elevated plasma apelin levels in untreated OSA may be beneficial in terms of glucose homeostasis (and hypertension - see below), there are putative deleterious consequences for oxidative stress-linked vascular disease, which warrant further investigation.

A tight positive correlation between apelin and tumour necrosis factor $\alpha$ (TNF $\alpha)$ expression in human adipose tissue has been reported (Daviaud et al. 2006). This link between apelin expression and inflammatory mediators may be particularly relevant in OSA where circulating levels of TNF $\alpha$ are known to be elevated (Vgontzas et al. 2000, Ciftci et al. 2004). CPAP therapy lowers circulating TNFa (Dorkova et al. 2008) and soluble TNF $\alpha$ receptor-1 levels (Arias et al. 2008). Reduced activation of the TNF $\alpha$ system may be another mechanism by which CPAP affects plasma apelin levels. 
Glucocorticoids may have a role in regulating apelin gene expression in adipocytes with suppression of apelin production in a dose-dependent manner (Wei et al. 2005). We have found that significant disruption to the HPA axis signalling occurs in untreated OSA with abnormalities in cortisol secretory dynamics (D E Henley, G M Russell, J A Douthwaite, S A Wood, F Buchanan, R Gibson, W W Woltersdorf, J R Catterall \& S L Lightman, unpublished data). This may in turn affect cortisol signalling and so disrupt the normal glucocorticoid inhibitory effect on apelin expression.

In the heart, apelin and APJ are highly expressed in myocardial and endothelial cells, and in the periphery, apelin is widely expressed in endothelial cells of blood vessels (Foldes et al. 2003, Kleinz \& Davenport 2004). Apelin has a role in modulating cardiac function and blood pressure. It is a potent positive inotropic agent (Szokodi et al. 2002), exerts hypotensive effects mediated through nitric oxide-dependent mechanisms (Tatemoto et al. 2001) and exhibits direct cardioprotective activity against ischaemia/reperfusion injury (Carpene et al. 2007). Endothelial dysfunction is well established in OSA (Atkeson \& Jelic 2008) and is ameliorated by CPAP therapy (Jelic et al. 2008). Hypoxia-induced myocardial/endothelial apelin expression has been demonstrated via hypoxia-inducible factor (HIF) pathways (Glassford et al. 2007, Ronkainen et al. 2007), and the HIF-1 pathway is activated in patients with OSA (Atkeson \& Jelic 2008). The pulmonary apelin-producing endothelium is particularly sensitive to hypoxia (Sheikh et al. 2008). Thus, upregulation of apelin in OSA may be a protective mechanism against OSA-associated hypertension and recurrent hypoxia/hypoxaemia, and endothelial dysfunction may represent the dominant mechanism for circulating plasma apelin levels in this patient group. Reversal of these factors by effective CPAP therapy is another means by which apelin may be down-regulated post-treatment.

We found no variation in plasma apelin levels throughout the 24-h period in untreated OSA, but a reduction was noted overnight following CPAP therapy. Nocturnal hypoxia/ hypoxaemia may be a significant factor, but does not explain the lower level found at $2200 \mathrm{~h}$, before the lights-out period. Interestingly, we did not find significant associations between oximetry parameters and nocturnal apelin levels (data not shown). Other factors such as inflammatory cytokines may also have a role. In addition, sympathetic nervous system (SNS) hyperactivity is well documented in OSA with high sympathetic drive present across the $24-\mathrm{h}$ period, even during daytime wakefulness and there is a reduction following CPAP (Narkiewicz \& Somers 2003). Chronic SNS activation may indirectly affect apelin expression via its effects on endothelial dysfunction, hypertension and hyperinsulinaemia (Narkiewicz \& Somers 2003). Direct effects of SNS activity on the apelin/APJ system have not been investigated. Why apelin should exhibit circadian variability is unclear. While apelin/APJ is expressed in the hypothalamus and pituitary gland, apelin localises with ACTH in corticotrophs
(Reaux-Le et al. 2007) and hypothalamic Apj mRNA expression is up-regulated by acute and chronic stress (O'Carroll et al. 2003); understanding of the exact role in HPA functioning is only now emerging (Newson et al. 2009) and the 24-h variability in plasma apelin levels in this study did not match the typical cortisol circadian rhythm.

We found a reduction in insulin levels and HOMA-IR with a concomitant increase in insulin sensitivity following CPAP therapy. However, there was no change in HOMAcalculated $\beta$-cell function, which may reflect relative changes in parasympathetic and sympathetic autonomic activity at both a pancreatic and peripheral tissue level (Gilon \& Henquin 2001). Markers of OSA severity together with anthropomorphic measurements correlated with OGTT insulin parameters. The OGTT, a dynamic test of the HPA axis (Reynolds et al. 2003), provided further evidence for HPA axis activation in untreated OSA (Henley et al. unpublished data) with a significant reduction in cortisol post-CPAP.

This study is the first to examine the effect of CPAP on plasma apelin levels in OSA patients. It is limited by its relatively small sample size and inability to recruit an appropriate control group. We are also unable to determine cardiovascular contributions. However, the dynamic changes in plasma apelin in response to OGTT suggest altered apelin regulation and secretory dynamics in untreated OSA. Whether the upregulation of apelin has predominantly beneficial or potentially negative effects should be the focus of future investigations, which should also include concurrent measures of cardiac status and endothelial dysfunction. This study highlights the importance of considering coexisting medical conditions in the interpretation of clinical data on apelin physiology/pathophysiology.

\section{Declaration of interest}

There is no conflict of interest that could be perceived as prejudicing the impartiality of the research reported.

\section{Funding}

This work has been supported by - Athelston and Amy Saw Medical Research Fellowship from the Faculty of Medicine, Dentistry and Health Sciences University of Western Australia; Western Australian Institute for Medical Research (WAIMR); Neuroendocrinology Charitable Trust; David Telling Charitable Trust; Charitable Trusts for the United Bristol Hospitals.

\section{Acknowledgements}

We would like to extend our thanks to Dr Adrian Kendrick and Ms Nadine Pillinger, Department of Respiratory Medicine, University Hospitals Bristol, for assistance in patient recruitment; to Mr Simon Littlewood and Ms Fiona Morgan, Department of Clinical Chemistry, University Hospitals Bristol, for assistance with cortisol assays; to Dr Becky Conway-Campbell and Dr Leslie Nolan, Henry Wellcome Laboratories for Integrative Neuroscience and Endocrinology, Bristol, for technical advice with the apelin assay; and Respironics (UK) Ltd, Chichester, United Kingdom for supplying the CPAP devices. 


\section{References}

Andersen CU, Markvardsen LH, Hilberg O \& Simonsen U 2009 Pulmonary apelin levels and effects in rats with hypoxic pulmonary hypertension. Respiratory Medicine DOI:10.1016/j.rmed.2009.05.011.

Arias MA, Garcia-Rio F, Alonso-Fernandez A, Hernanz A, Hidalgo R, Martinez-Mateo V, Bartolome S \& Rodriguez-Padial L 2008 CPAP decreases plasma levels of soluble tumour necrosis factor-alpha receptor 1 in obstructive sleep apnoea. European Respiratory Journal 32 1009-1015.

Atkeson A \& Jelic S 2008 Mechanisms of endothelial dysfunction in obstructive sleep apnea. Vascular Health and Risk Management 4 1327-1335.

Boucher J, Masri B, Daviaud D, Gesta S, Guigne C, Mazzucotelli A, Castan-Laurell I, Tack I, Knibiehler B, Carpene C et al. 2005 Apelin, a newly identified adipokine up-regulated by insulin and obesity. Endocrinology 146 1764-1771.

Bradley TD \& Floras JS 2009 Obstructive sleep apnoea and its cardiovascular consequences. Lancet 373 82-93.

Buckley TM \& Schatzberg AF 2005 On the interactions of the hypothalamicpituitary-adrenal (HPA) axis and sleep: normal HPA axis activity and circadian rhythm, exemplary sleep disorders. Journal of Clinical Endocrinology and Metabolism 90 3106-3114

Carpene C, Dray C, Attane C, Valet P, Portillo MP, Churruca I, Milagro FI \& Castan-Laurell I 2007 Expanding role for the apelin/APJ system in physiopathology. Journal of Physiology and Biochemistry 63 359-374.

Chandrasekaran B, Dar O \& McDonagh T 2008 The role of apelin in cardiovascular function and heart failure. European Journal of Heart Failure $10725-732$.

Chong KS, Gardner RS, Morton JJ, Ashley EA \& McDonagh TA 2006 Plasma concentrations of the novel peptide apelin are decreased in patients with chronic heart failure. European Journal of Heart Failure $\mathbf{8}$ 355-360.

Ciftci TU, Kokturk O, Bukan N \& Bilgihan A 2004 The relationship between serum cytokine levels with obesity and obstructive sleep apnea syndrome. Cytokine 28 87-91.

Collop N 2007 The effect of obstructive sleep apnea on chronic medical disorders. Cleveland Clinic Journal of Medicine 74 72-78.

Coughlin SR, Mawdsley L, Mugarza JA, Calverley PM \& Wilding JP 2004 Obstructive sleep apnoea is independently associated with an increased prevalence of metabolic syndrome. European Heart Journal 25 735-741.

Daviaud D, Boucher J, Gesta S, Dray C, Guigne C, Quilliot D, Ayav A, Ziegler O, Carpene C, Saulnier-Blache JS et al. 2006 TNFalpha up-regulates apelin expression in human and mouse adipose tissue. FASEB Journal 20 1528-1530.

Dorkova Z, Petrasova D, Molcanyiova A, Popovnakova M \& Tkacova R 2008 Effects of continuous positive airway pressure on cardiovascular risk profile in patients with severe obstructive sleep apnea and metabolic syndrome. Chest 134 686-692.

Dray C, Knauf C, Daviaud D, Waget A, Boucher J, Buleon M, Cani PD, Attane C, Guigne C, Carpene C et al. 2008 Apelin stimulates glucose utilization in normal and obese insulin-resistant mice. Cell Metabolism $\mathbf{8}$ 437-445.

Erdem G, Dogru T, Tasci I, Sonmez A \& Tapan S 2008 Low plasma apelin levels in newly diagnosed type 2 diabetes mellitus. Experimental and Clinical Endocrinology and Diabetes 116 289-292.

Ernst KV, Ashley EA, Charo D, Kawana M, Fajardo D \& Bermstein D 2006 Apelin regulates cardiac contractility and rescues neurohormonal heart failure. Journal of Cardiac Failure 12 S1.

Foldes G, Horkay F, Szokodi I, Vuolteenaho O, Ilves M, Lindstedt KA, Mayranpaa M, Sarman B, Seres L, Skoumal R et al. 2003 Circulating and cardiac levels of apelin, the novel ligand of the orphan receptor APJ, in patients with heart failure. Biochemical and Biophysical Research Communications 308 480-485.

Gilon P \& Henquin JC 2001 Mechanisms and physiological significance of the cholinergic control of pancreatic beta-cell function. Endocrine Reviews 22 $565-604$.
Glassford AJ, Yue P, Sheikh AY, Chun HJ, Zarafshar S, Chan DA, Reaven GM, Quertermous T \& Tsao PS 2007 HIF-1 regulates hypoxia- and insulininduced expression of apelin in adipocytes. American Journal of Physiology. Endocrinology and Metabolism 293 E1590-E1596.

Goetze JP, Rehfeld JF, Carlsen J, Videbaek R, Andersen CB, Boesgaard S \& Friis-Hansen L 2006 Apelin: a new plasma marker of cardiopulmonary disease. Regulatory Peptides 133 134-138.

Harsch IA, Schahin SP, Radespiel-Troger M, Weintz O, Jahreiss H, Fuchs FS, Wiest GH, Hahn EG, Lohmann T, Konturek PC et al. 2004 Continuous positive airway pressure treatment rapidly improves insulin sensitivity in patients with obstructive sleep apnea syndrome. American Journal of Respiratory and Critical Care Medicine 169 156-162.

Hashimoto T, Kihara M, Imai N, Yoshida S, Shimoyamada H, Yasuzaki H, Ishida J, Toya Y, Kiuchi Y, Hirawa N et al. 2007 Requirement of apelinapelin receptor system for oxidative stress-linked atherosclerosis. American Journal of Pathology 171 1705-1712.

Heinonen MV, Purhonen AK, Miettinen P, Paakkonen M, Pirinen E, Alhava E, Akerman K \& Herzig KH 2005 Apelin, orexin-A and leptin plasma levels in morbid obesity and effect of gastric banding. Regulatory Peptides 130 7-13.

Henley DE, Leendertz JA, Russell GM, Wood SA, Taheri S, Woltersdorf WW \& Lightman SL 2009 Development of an automated blood sampling system for use in humans. Journal of Medical Engineering and Technology 33 199-208.

Hosoya M, Kawamata Y, Fukusumi S, Fujii R, Habata Y, Hinuma S, Kitada C, Honda S, Kurokawa T, Onda $\mathrm{H}$ et al. 2000 Molecular and functional characteristics of APJ. Tissue distribution of mRNA and interaction with the endogenous ligand apelin. Journal of Biological Chemistry $\mathbf{2 7 5}$ 21061-21067.

Jelic S, Padeletti M, Kawut SM, Higgins C, Canfield SM, Onat D, Colombo PC, Basner RC, Factor P \& LeJemtel TH 2008 Inflammation, oxidative stress, and repair capacity of the vascular endothelium in obstructive sleep apnea. Circulation 117 2270-2278.

Kawamata Y, Habata Y, Fukusumi S, Hosoya M, Fujii R, Hinuma S, Nishizawa N, Kitada C, Onda H, Nishimura O et al. 2001 Molecular properties of apelin: tissue distribution and receptor binding. Biochimica et Biophysica Acta 1538 162-171.

Kleinz MJ \& Davenport AP 2004 Immunocytochemical localization of the endogenous vasoactive peptide apelin to human vascular and endocardial endothelial cells. Regulatory Peptides 118 119-125.

Kleinz MJ \& Davenport AP 2005 Emerging roles of apelin in biology and medicine. Pharmacology \& Therapeutics 107 198-211.

Lee DK, Saldivia VR, Nguyen T, Cheng R, George SR \& O'dowd BF 2005 Modification of the terminal residue of apelin-13 antagonizes its hypotensive action. Endocrinology 146 231-236.

Li L, Yang G, Li Q, Tang Y, Yang M, Yang H \& Li K 2006 Changes and relations of circulating visfatin, apelin, and resistin levels in normal, impaired glucose tolerance, and type 2 diabetic subjects. Experimental and Clinical Endocrinology and Diabetes 114 544-548.

Narkiewicz K \& Somers VK 2003 Sympathetic nerve activity in obstructive sleep apnoea. Acta Physiologica Scandinavica 177 385-390.

Newson MJ, Roberts EM, Pope GR, Lolait SJ \& O'Carroll AM 2009 The effects of apelin on hypothalamic-pituitary-adrenal axis neuroendocrine function are mediated through corticotrophin-releasing factor- and vasopressin-dependent mechanisms. Journal of Endocrinology 202 123-129.

O'Carroll AM, Don AL \& Lolait SJ 2003 APJ receptor mRNA expression in the rat hypothalamic paraventricular nucleus: regulation by stress and glucocorticoids. Journal of Neuroendocrinology 15 1095-1101.

O'dowd BF, Heiber M, Chan A, Heng HH, Tsui LC, Kennedy JL, Shi X, Petronis A, George SR \& Nguyen T 1993 A human gene that shows identity with the gene encoding the angiotensin receptor is located on chromosome 11. Gene 136 355-360.

Peter JH, Koehler U, Grote L \& Podszus T 1995 Manifestations and consequences of obstructive sleep apnoea. European Respiratory Journal $\mathbf{8}$ 1572-1583.

Punjabi NM 2008 The epidemiology of adult obstructive sleep apnea. Proceedings of the American Thoracic Society 5 136-143. 
Reaux-Le GA, vear-Perez R, Zizzari P, Epelbaum J, Bluet-Pajot MT \& Llorens-Cortes C 2007 Cellular localization of apelin and its receptor in the anterior pituitary: evidence for a direct stimulatory action of apelin on ACTH release. American Journal of Physiology. Endocrinology and Metabolism 292 E7-E15.

Rechtschaffen A \& Kales A eds 1968 A Manual of Standardised Terminology, Techniques and Scoring System for Sleep Stages of Human Subjects. Los Angeles: Brain Information Service/Brain Research Institute.

Reynolds RM, Syddall HE, Walker BR, Wood PJ \& Phillips DI 2003 Predicting cardiovascular risk factors from plasma cortisol measured during oral glucose tolerance tests. Metabolism 52 524-527.

Ronkainen VP, Ronkainen JJ, Hanninen SL, Leskinen H, Ruas JL, Pereira T, Poellinger L, Vuolteenaho O \& Tavi P 2007 Hypoxia inducible factor regulates the cardiac expression and secretion of apelin. FASEB Journal 21 1821-1830.

Seicean S, Kirchner HL, Gottlieb DJ, Punjabi NM, Resnick H, Sanders M, Budhiraja R, Singer M \& Redline S 2008 Sleep-disordered breathing and impaired glucose metabolism in normal-weight and overweight/ obese individuals: the Sleep Heart Health Study. Diabetes Care 31 1001-1006.

Seyedabadi M, Goodchild AK \& Pilowsky PM 2002 Site-specific effects of apelin-13 in the rat medulla oblongata on arterial pressure and respiration. Autonomic Neurosience 101 32-38.

Sheikh AY, Chun HJ, Glassford AJ, Kundu RK, Kutschka I, Ardigo D, Hendry SL, Wagner RA, Chen MM, Ali ZA et al. 2008 In vivo genetic profiling and cellular localization of apelin reveals a hypoxia-sensitive, endothelial-centered pathway activated in ischemic heart failure. American Journal of Physiology. Heart and Circulatory Physiology 294 H88-H98.

Szokodi I, Tavi P, Foldes G, Voutilainen-Myllyla S, Ilves M, Tokola H, Pikkarainen S, Piuhola J, Rysa J, Toth M et al. 2002 Apelin, the novel endogenous ligand of the orphan receptor APJ, regulates cardiac contractility. Circulation Research 91 434-440.
Tasci I, Dogru T, Naharci I, Erdem G, Yilmaz MI, Sonmez A, Bingol N, Kilic S, Bingol S \& Erikci S 2007 Plasma apelin is lower in patients with elevated LDL-cholesterol. Experimental and Clinical Endocrinology and Diabetes 115 428-432.

Tasci I, Erdem G, Ozgur G, Tapan S, Dogru T, Genc H, Acikel C, Ozgurtas T \& Sonmez A 2009 LDL-cholesterol lowering increases plasma apelin in isolated hypercholesterolemia. Atherosclerosis 204 222-228.

Tatemoto K, Hosoya M, Habata Y, Fujii R, Kakegawa T, Zou MX, Kawamata Y, Fukusumi S, Hinuma S, Kitada C et al. 1998 Isolation and characterization of a novel endogenous peptide ligand for the human APJ receptor. Biochemical and Biophysical Research Communications 251 471-476.

Tatemoto K, Takayama K, Zou MX, Kumaki I, Zhang W, Kumano K \& Fujimiya M 2001 The novel peptide apelin lowers blood pressure via a nitric oxide-dependent mechanism. Regulatory Peptides 99 87-92.

Vgontzas AN, Papanicolaou DA, Bixler EO, Hopper K, Lotsikas A, Lin HM, Kales A \& Chrousos GP 2000 Sleep apnea and daytime sleepiness and fatigue: relation to visceral obesity, insulin resistance, and hypercytokinemia. Journal of Clinical Endocrinology and Metabolism 85 1151-1158.

Wallace TM, Levy JC \& Matthews DR 2004 Use and abuse of HOMA modeling. Diabetes Care 27 1487-1495.

Wei L, Hou X \& Tatemoto K 2005 Regulation of apelin mRNA expression by insulin and glucocorticoids in mouse 3T3-L1 adipocytes. Regulatory Peptides 132 27-32.

World Health Organisation 2000 Obesity: Preventing and Managing the Global Epidemic. Geneva: World Health Organisation.

Received in final form 23 July 2009

Accepted 30 July 2009

Made available online as an Accepted Preprint

30 July 2009 